\title{
Increased fibroblast functionality on CNN2-loaded titania nanotubes
}

This article was published in the following Dove Press journal:

International Journal of Nanomedicine

22 February 2012

Number of times this article has been viewed

\section{Hongbo Wei* \\ Shuyi Wu* \\ Zhihong Feng \\ Wei Zhou \\ Yan Dong \\ Guofeng Wu \\ Shizhu Bai \\ Yimin Zhao}

Department of Prosthodontics, School of Stomatology, Fourth Military Medical University, Xi'an, People's Republic of China

*These authors contributed equally to this work
Correspondence: Yimin Zhao

Department of Prosthodontics, School of Stomatology, Fourth Military Medical University, Changle West Road I45,

Xi'an 7I0032, People's Republic of China

Tel +86298477 600 I

$\mathrm{Fax}+862983223047$

Email zhaoym@fmmu.edu.cn

Shizhu Bai

Department of Prosthodontics, School of Stomatology, Fourth Military Medical University, Changle West Road I45,

Xi'an 710032, People's Republic of China

Tel +860298477 6465

Fax +86 02983223047

Email shizhu1976@gmail.com
Abstract: Infection and epithelial downgrowth are major problems associated with maxillofacial percutaneous implants. These complications are mainly due to the improper closure of the implant-skin interface. Therefore, designing a percutaneous implant that better promotes the formation of a stable soft tissue biologic seal around percutaneous sites is highly desirable. Additionally, the fibroblast has been proven to play an important role in the formation of biologic seals. In this study, titania nanotubes were filled with $11.2 \mathrm{kDa}$ C-terminal CCN2 (connective tissue growth factor) fragment, which could exert full CCN2 activity to increase the biological functionality of fibroblasts. This drug delivery system was fabricated on a titanium implant surface. CCN2 was loaded into anodized titania nanotubes using a simplified lyophilization method and the loading efficiency was approximately $80 \%$. Then, the release kinetics of CCN2 from these nanotubes was investigated. Furthermore, the influence of CCN2-loaded titania nanotubes on fibroblast functionality was examined. The results revealed increased fibroblast adhesion at $0.25,0.5,1,2,4$, and 24 hours, increased fibroblast viability over the course of 5 days, as well as enhanced actin cytoskeleton organization on CCN2-loaded titania nanotubes surfaces compared to uncoated, unmodified counterparts. Therefore, the results from this in vitro study demonstrate that CCN2-loaded titania nanotubes have the ability to increase fibroblast functionality and should be further studied as a method of promoting the formation of a stable soft tissue biologic seal around percutaneous sites.

Keywords: anodization, titania nanotubes, adhesion, connective tissue growth factor, fibroblast

\section{Introduction}

The long-term success of percutaneous implants relies on the formation of a stable soft tissue biologic seal around the percutaneous site. ${ }^{1-3}$ Infection and epithelial growth are two of the principal causes of the failure of percutaneous implants. ${ }^{1,3-9}$ A biosynthetic soft tissue seal can act as a barrier against epithelial downgrowth and bacterial invasion on subepithelial connective tissues and the implant interface. ${ }^{1,10,11}$

The fibroblast plays an important role in the formation of a biologic seal. The biologic seal of skin is provided by both the epidermis and the dermis, which mainly consist of fibroblasts that produce extracellular matrix (ECM) and various essential components of connective tissues, including glycosaminoglycans and collagen in fibrous tissue. ${ }^{12,13}$ Previous studies have demonstrated that the quality of the connective tissue at the percutaneous area is more important than the quality of the epithelial attachment for the long-term success of maxillofacial implants. ${ }^{11,14}$ Therefore, expediting the attachment and growth of fibroblasts could promote the 
formation of a permanent biologic seal at the percutaneous area and prevent contamination of the implant. ${ }^{15}$

Currently, the percutaneous surfaces of implants are often made smooth to prevent the adhesion of bacteria. ${ }^{11}$ Upon healing, the wound closure is likely to be generated by the contraction of fibrous connective tissues during the healing process. However, such smooth surfaces have been shown to lead to detrimental capsule. ${ }^{9,11}$ Current methods to improve the formation of a biologic seal are aimed at preventing bacterial infection rather than promoting skin growth around the percutaneous site. These methods include altering surgical techniques, modifying the implant design, and coating its surface. ${ }^{16}$ Coating approaches have been shown to increase the antibacterial ability of implants by using fibroblast growth factor 2-embedded apatite composites ${ }^{17}$ and silver nanoparticles. ${ }^{18,19}$ Although these coatings reduced the presence of bacteria compared to their uncoated counterparts, the infection rate was still high and there was no reported effect on biologic seal formation. Therefore, there is a need for alternate ways to improve the formation of a biologic seal and decrease infection rates. An alternative strategy is to create a growth factor coating that can promote fibroblast growth around the percutaneous site, which would not only provide a stable biological seal but would also provide a permanent barrier against bacterial infection. By optimizing the surface structure, as well as the growth factor loading capacity and release rate, biosynthetic coating materials can achieve both of these goals.

A more suitable drug carrier for creating a growth factoreluting implant coating is titania nanotubes, which have already been shown to exhibit very good biomechanical compatibility. ${ }^{16,20-22}$ This material has served as a carrier for several agents such as proteins, antibacterial compounds, and other drugs. ${ }^{18,22-25}$ In addition, titania nanotubes are highly ordered with different diameters and lengths that can be easily fabricated to specification. ${ }^{26} \mathrm{CCN} 2$ (connective tissue growth factor) is an excellent candidate for loading drugs. CCN2 has been shown to be sufficient to promote fibroblast adhesion, and it also promotes fibroblast proliferation. ${ }^{27-33}$ Recombinant human CNN2, a lower molecular weight isoform containing the $11.2 \mathrm{kDa}$ C-terminal portion of the full length CNN2 protein, exerts full heparin binding, cell adhesion, and mitogenic CNN2 activity. CNN2 is noncytotoxic at suitable doses and has satisfactory stability. Because the required dose of CNN2 for biological activity is extremely low, it is possible to fabricate coatings with extended delivery times by controlling CNN2 release.
In this study, the purpose was to investigate whether CNN2 could be incorporated into the nanotubes controllably and to evaluate the effect of CNN2-loaded titania nanotubes on the biological responses of fibroblasts.

\section{Materials and methods Substrate preparation and anodization}

Circular pure titanium sheets $1 \mathrm{~mm}$ thick and $10 \mathrm{~mm}$ in diameter were used as the substrates. The substrates were ultrasonically cleaned in acetone, followed by ethanol, and deionized water for 10 minutes, respectively. They were anodized for 120 minutes in an electrolyte containing 0.3 weight percent hydrofluoric acid and $1 \mathrm{M} / \mathrm{L}$ phosphoric acid using a direct current power supply with a platinum electrode as the cathode. The anodization process took place at a constant voltage of $20 \mathrm{~V}$ and $25 \mathrm{~V}$. The titanium substrates were rinsed with large amounts of deionized water immediately after anodization, air dried, and sterilized under ultraviolet light for 3 hours per substrate side prior to cell culture experiments.

\section{Surface characterization}

\section{Topography and composition of the surface}

Structural characterization of the titania nanotube surfaces was performed using a field emission scanning electron microscope (S-4800; Hitachi High Technologies, Tokyo, Japan). Images with a range of scan sizes were acquired from the top and cross-sections.

\section{Roughness}

For quantitative surface roughness analysis, atomic force microscopy (Veeco Germany, Mannheim, Germany) was performed on both nanotubular and unmodified surfaces. Measurements were conducted in ambient air with a scan rate of $2 \mathrm{~Hz}$. The scan area was $0.5 \times 0.5 \mu \mathrm{m}^{2}$. Image analysis software was used to generate micrographs and to quantitatively compare the root mean square roughness and relative surface area of the nanotubular (20 V voltage) and unmodified titanium substrates.

\section{Contact angle and surface free energy}

Contact angle measurements were carried out by the sessile drop method on an EasyDrop Standard instrument (KRUSS $\mathrm{GmbH}$, Hamburg, Germany) at room temperature. Three different liquids, ultrapure water, and diiodomethane were in the contact angle measurements. The surface free energy and its components were calculated using the van Oss acid-base method. The contact angle was measured by analyzing the 
drop shape surface and the calculations of free energy using DSA1 software (KRUSS).

\section{Fabrication of the titania nanotubular CNN2-loaded coating and release kinetics \\ Filling of the nanotubes}

A simplified lyophilization method was chosen to load recombinant human CNN2 (PeproTech, Rocky Hill, NJ) into the nanotubes. This recombinant human CCN2, an $11.2 \mathrm{kDa}$ protein of 98 amino acid residues, is Escherichia coli-derived. A total of $5 \mu \mathrm{L}$ of protein solution was pipetted onto the surface and spread to ensure even coverage. The surfaces were then allowed to dry under vacuum at room temperature in a freeze dryer for 2 hours. After drying, the loading step was repeated until the appropriate amount of protein (25 $\mathrm{ng}$ or $50 \mathrm{ng}$ ) was loaded. After the final drying step, excess drug was rinsed from the surface by pipetting $500 \mathrm{~mL}$ of phosphate buffered saline (PBS) to analyze the loading efficiency.

\section{Release of CCN2}

To measure the release of the protein from the nanotubes, the surfaces were immersed in $500 \mu \mathrm{L}$ of PBS in a 48 -well plate at room temperature with orbital shaking at $70 \mathrm{rpm}$. A total of $200 \mu \mathrm{L}$ of samples was taken (replaced with $200 \mathrm{~mL}$ of fresh PBS) after specific intervals of time (15 minutes) for up to 120 minutes to determine the release kinetics. The concentration of protein was monitored using a CCN2 enzyme-linked immunosorbent assay (PeproTech). The loading efficiency and the release kinetics for different doses of drug coatings were determined.

\section{Cell culture}

Primary human skin fibroblasts were isolated from newborn foreskin as previously described. ${ }^{34}$ Cells were used at passages three to eight. Human skin fibroblasts were cultured separately in HyClone Dulbecco's Modified Eagle Medium (Thermo Fisher Scientific Inc, Pittsburg, PA) with HyClone $10 \%$ fetal bovine serum (Thermo Fisher) and 1\% penicillin/ streptomycin (Sigma-Aldrich Corporation, St Louis, MO) under standard culture conditions at $37^{\circ} \mathrm{C}$ in humidified $5 \%$ carbon dioxide $/ 95 \%$ air. When the density of fibroblasts reached a suitable population, they were seeded onto the experimental substrates (50 ng CCN2-loaded $20 \mathrm{~V}$ voltage nanotubular coated surface, $20 \mathrm{~V}$ voltage nanotubular surface, and unmodified surface were chosen as the experimental substrates), which were placed in a 48 -well polystyrene plate and stored in a carbon dioxide incubator. The cell media was replaced every 2 days.

\section{Cell viability assay}

The concentration of cells seeded onto the specimen substrate was 1000 cells $\mathrm{cm}^{-2}$ per substrate for cell viability experiments in a standard 48-well culture plate under standard cell conditions. Cell viability was assayed with a Cell Counting Kit-8 (Dojindo Molecular Technologies Inc, Kumamoto, Japan). Briefly, after 1, 3, and 5 days of culture, culture medium was moved, and $200 \mathrm{~mL}$ of fresh culture medium mixed with $20 \mu \mathrm{L}$ of Cell Counting Kit- 8 reagent was added into each well. Then, the samples were incubated for 2 hours according to the manufacturer's instructions. In addition, the same volume of culture medium and Cell Counting Kit-8 reagent without cells was also incubated as the background control. An aliquot $(150 \mathrm{~mL})$ of incubated medium was pipetted into a 96-well plate and the absorbance at $450 \mathrm{~nm}$ was measured for each well as above. All experiments were performed with a sample size of $n=6$.

\section{Cell adhesion assay}

Cell adhesion was assayed with a live cell labeling kit (Cellstain-CFSE; Dojindo). The fibroblasts $\left(10^{7}\right.$ cells $\left./ \mathrm{mL}\right)$ were labeled with carboxyfluorescein diacetate succinimyl ester $(20 \mu \mathrm{M} / \mathrm{mL})$ at $37^{\circ} \mathrm{C}$ for 15 minutes. We pelleted cells by centrifugation and washed the cells by resuspending the pellet in fresh media. This process was repeated for a total of three washes. Then the fibroblasts were seeded at a density of 25,000 cells per substrate for adhesion experiments in a standard 48-well culture plate under standard cell conditions. At the indicated time points $(0,0.25,0.5,1,2,4$, and 24 hours), substrates were rinsed in PBS to remove any nonadherent cells and $200 \mathrm{~mL}$ of sodium dodecyl sulfate/ Tris (hydroxymethyl) aminomethane hydrochloride solution was added into each well to dissolve the fluorescent dye. An aliquot $(150 \mathrm{~mL})$ from each well was transferred to a new 96-well plate. Fluorescence was measured using a fluorometer plate reader (Synergy HT; BioTek, Winooski, VT). All experiments were performed with a sample size of $n=6$.

\section{Immunofluorescence of cytoskeletal actin}

Epifluorescence microscopy was used to compare the morphological alterations both in regard to the organization of the actin cytoskeleton and cellular shape. The distribution of actin was observed at 4 hours, 1 day, and 3 days of culture. After this period of time, the cells were washed with PBS and fixed in a $4 \%$ paraformaldehyde solution for 15 minutes. 
The samples were then washed in PBS and treated with $0.1 \%$ Triton $\mathrm{X}-100$ ( 5 minutes at room temperature). The samples were then incubated at $37^{\circ} \mathrm{C}$ for 5 minutes in $1 \%$ bovine serum albumin/PBS, followed by washing with PBS and incubation with phalloidin-fluorescein isothiocyanate (Sigma-Aldrich) for 1 hour at $37^{\circ} \mathrm{C}$. Actin staining was visualized and analyzed under a laser scanning confocal microscope (FV1000; Olympus Corporation, Tokyo, Japan).

\section{Statistical analyses}

All experiments were run in triplicate (at least) and repeated a minimum of three separate times. Experimental data were analyzed statistically using analysis of variance followed by Student's $t$-tests. Statistical significance was considered at $P<0.05$.

\section{Results}

\section{Surface characterization}

Scanning electron micrographs (Figure 1A and B) showed that the nanotubes were highly ordered and vertically aligned with a diameter of approximately $100 \mathrm{~nm}$ (20 V voltage) and $120 \mathrm{~nm}$ ( $25 \mathrm{~V}$ voltage). It was estimated that the nanotubes were between $400 \mathrm{~nm}$ and $500 \mathrm{~nm}$ deep from the crosssectional image (Figure 1A and B). Representative atomic force microscope images of unmodified and $20 \mathrm{~V}$ voltage nanotubular anodized titanium were characterized by root mean square roughness and relative surface area (Figure $2 \mathrm{~A}$ and B; Table 1). The results showed that the unmodified titanium surface was relatively smooth compared with the $100 \mathrm{~nm}$ diameter nanotubular anodized titanium surface.

Surface energy calculations from contact angle measurements indicated that the greater surface roughness at the nanoscale level correlated with an increased surface energy. Specifically, the $100 \mathrm{~nm}$ diameter nanotubular titanium had a surface energy significantly higher than that of unmodified titanium (Table 2).

\section{Analysis of the CCN2 loading efficiency and release curve}

The loading efficiency was expressed as the percentage of loaded drug after washing according to the following formula:

$$
\eta=\frac{D_{0}-D_{r}}{D_{0}}
$$

where $\eta$ is loading efficiency, $D_{0}$ is drug dose used to fill the nanotubes, and $\mathrm{D}_{\mathrm{r}}$ is the drug dose in the rinse solution.

Loading efficiencies for $100 \mathrm{~nm}$ diameter nanotubes loaded with $25 \mathrm{ng}$ and $50 \mathrm{ng}$ of CCN2 and $120 \mathrm{~nm}$ diameter nanotubes loaded with $50 \mathrm{ng}$ of CCN2 are shown in Figure $3 \mathrm{~A}$. These results indicated that $77 \%, 81 \%$, and $76 \%$ of the drug, respectively, was retained in the nanotubes after an initial wash.

Figure 3B-D show the CCN2 release kinetics from the coating in PBS with orbital shaking. The amount of released CCN2 diminished gradually with immersion time. As expected, there was a slower and more sustained release from the $100 \mathrm{~nm}$ diameter nanotubes loaded with $50 \mathrm{ng}$ CCN2 compared to $100 \mathrm{~nm}$ diameter nanotubes loaded with $25 \mathrm{ng}$ CCN2 and $120 \mathrm{~nm}$ diameter nanotubes loaded with $50 \mathrm{ng}$. Kinetic analysis of the nanotubes loaded with $50 \mathrm{ng}$ of CCN2 indicated that the maximum drug had eluted within 105 minutes. Alternately, kinetic analysis of the $100 \mathrm{~nm}$ diameter nanotubes loaded with $25 \mathrm{ng}$ of CCN2 and the $120 \mathrm{~nm}$ diameter nanotubes loaded with $50 \mathrm{ng}$ indicated that the maximum drug in both had eluted within 90 minutes.

\section{Cell viability}

The cell viability of fibroblasts grown on the above substrates and the corresponding incubation times are summarized in Figure 4. As shown, cell growth on the CCN2-loaded titania nanotubular surface was significantly higher than the other
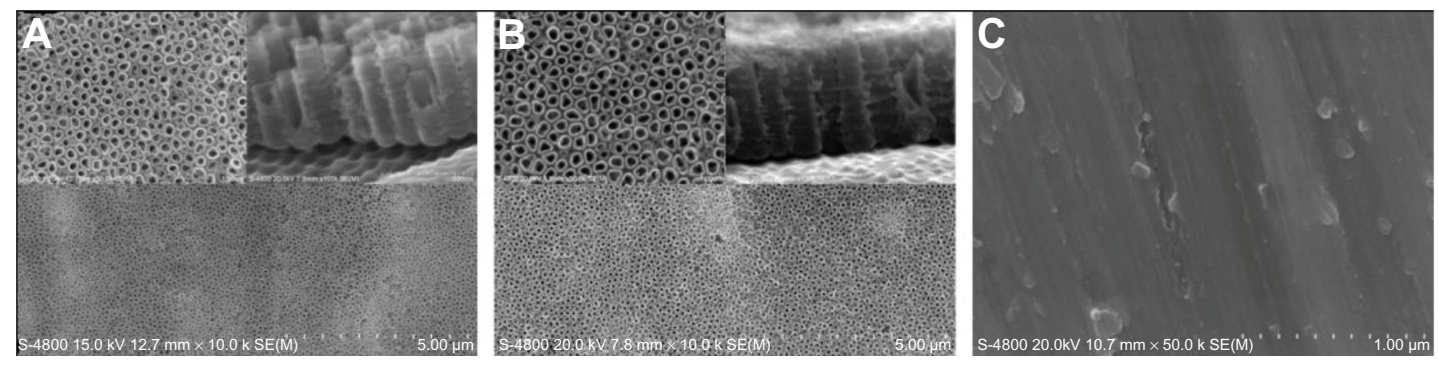

Figure I Scanning electron microscope images of (A) $20 \mathrm{~V}$ voltage nanotubular anodized titanium under low magnification and high magnification, and nanotubular anodized titanium cross-sections; (B) $25 \mathrm{~V}$ voltage nanotubular anodized titanium under low magnification and high magnification, and nanotubular anodized titanium cross-sections; and (C) unmodified titanium. 

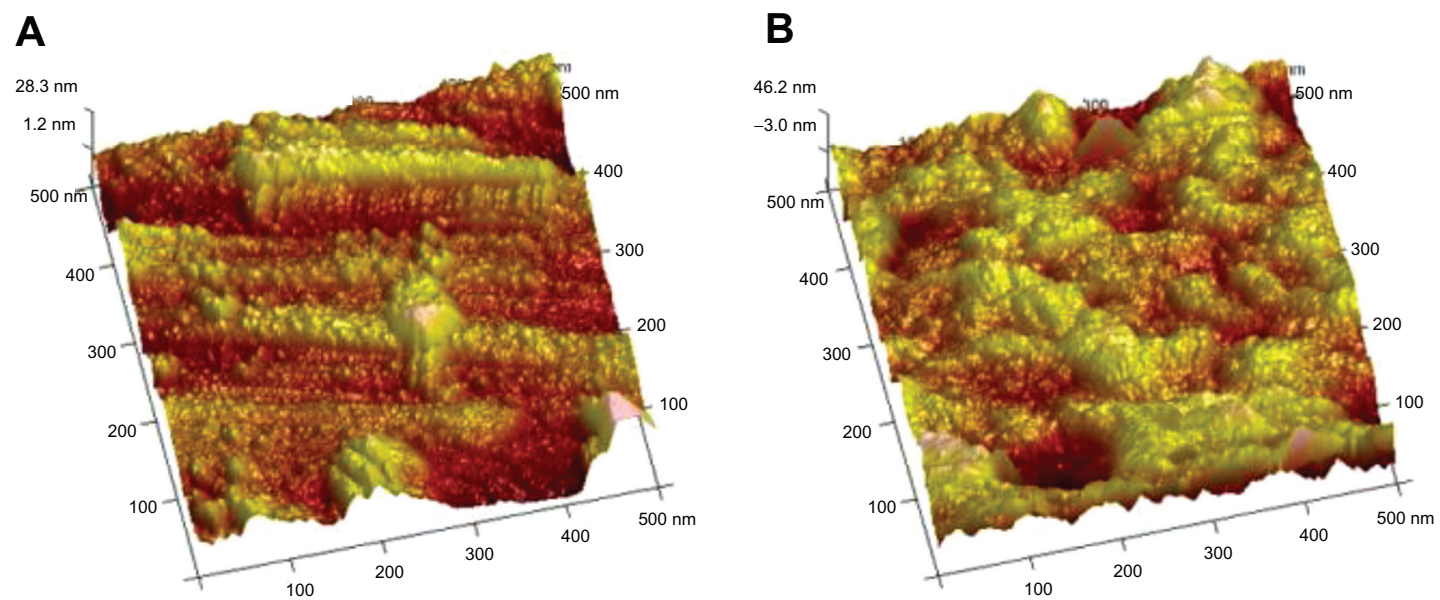

Figure 2 Atomic force microscope images of $(\mathbf{A})$ nanotubular anodized titanium ( $20 \mathrm{~V}$ voltage) and (B) unmodified titanium.

two kinds of surfaces at days 1,3 , and 5 after incubation $(P<0.05)$. However, the difference between the nanotubular surface and the unmodified surface was not obvious from statistical analysis. This finding indicates that titania nanotubes with a CCN2 coating release growth factor in a sustainable manner that promotes cell mitosis continuously.

\section{Fibroblast adhesion}

Results of the present study demonstrate increased fibroblast adhesion to the CCN2-loaded titania nanotubular surface compared to nanotubular titanium and unmodified titanium surfaces (Figure 5). There was not a statistically significant $(P<0.05)$ difference in fibroblast adhesion between the nanotube anodized titanium compared to unmodified titanium. As expected, the results also showed increased $(P<0.05)$ adhesion of fibroblasts to the CCN2-loaded titania nanotubular surface.

\section{Morphological alterations and cytoskeletal actin}

These results showed a strong initial interaction between the cells and the modified surface (Figure 6). Notably, the morphology of cells grown on these surfaces was different after different times during the culturing. At 4 hours, many stress fibers were apparent around the periphery of the cells

Table I Surface roughness of unmodified and nanotubular titanium $(20 \mathrm{~V}$ voltage) surfaces

\begin{tabular}{lll}
\hline Substrates & $\begin{array}{l}\text { Relative surface } \\
\text { area }\left(\mu \mathbf{m}^{2}\right)\end{array}$ & $\begin{array}{l}\text { Root mean square } \\
\text { roughness }(\mathbf{n m})\end{array}$ \\
\hline Unmodified titanium & $0.3260 \pm 0.017$ & $6.940 \pm 0.75$ \\
Nanotubular titanium & $0.521 \pm 0.045^{*}$ & $9.340 \pm 0.59^{*}$ \\
\hline
\end{tabular}

Note: $* P<0.05$ nanotubular titanium compared with unmodified titanium. on the CCN2-loaded titania nanotubular surface. However, the cells grown on the other two kinds of surfaces at this point, whilst showing lamella formation, had fewer stress fibers. Within 1 day, cells on the CCN2-loaded titania nanotubular surface displayed thick, contractile stress fibers. In contrast, the cells on the other two surfaces had noticeably fewer contractile stress fibers. Within 3 days, cells on the CCN2-loaded titania nanotubular surface exhibited thick stress fibers and a more voluminous cell body and began to become confluent, whereas fewer cells on the other two surfaces were confluent.

\section{Discussion}

CCN2-loaded titania nanotubular surfaces promoted excellent cellular responses throughout the 5-day study period. At $0.25,0.5,1,2$, and 4 hours, the number of cells initially adhered to the $\mathrm{CCN} 2$ coating were higher than the other two surfaces. Cells adhered to the implant surfaces by attaching to the ECM, and cytoskeletal organization is an important criterion of cell-ECM interactions. Cytoskeletal organization is also extremely important in modulating cell morphology, motility, and adhesion. In the present study, when the cell initially responded to the $\mathrm{CCN} 2$-coated nanotubular surface, the cytoskeleton was formed faster for these cells than for those reacting to control surfaces. Additionally, with time, denser and thicker parallel-oriented stress fibers were noticed on the surface. Therefore, there were most likely more stable cell substrate interactions on the CCN2-coated surface.

Infection and epithelial downgrowth are major problems with percutaneous implants and both are mainly due to the improper closure of the implant-soft tissue interface. ${ }^{16}$ Most current methods are aimed at preventing bacterial infection rather than repairing the lack of connective tissue growth 
Table 2 Contact angle (in degrees) and surface energy components of unmodified and nanotubular titanium (20 V voltage) surfaces (in $\mathrm{mj} / \mathrm{m}^{2}$ )

\begin{tabular}{|c|c|c|c|c|c|c|c|c|}
\hline \multirow[t]{2}{*}{ Substrate } & \multicolumn{3}{|c|}{ Contact angle } & \multicolumn{5}{|c|}{ Surface energy components } \\
\hline & Water & Formamide & Diiodomethane & $\lambda_{s}^{L W}$ & $\lambda_{\mathrm{s}}^{+}$ & $\lambda_{\mathrm{s}}^{-}$ & $\lambda_{s}^{A B}$ & $\lambda_{\mathrm{s}}$ \\
\hline Unmodified titanium & 60.6 & 52.2 & 19.3 & 46.6 & 0.3 & 24.8 & -5.4 & $\overline{41.2}$ \\
\hline Nanotubular titanium & 28.7 & 16.2 & 20.7 & 47.8 & 0.4 & 2.8 & 7.8 & 55.6 \\
\hline
\end{tabular}

around the percutaneous site. ${ }^{18,24} \mathrm{~A}$ better strategy is to create an implant surface with a growth factor coating that can promote connective tissue growth around the surgical site, which would not only prevent epithelial downgrowth but also provide a permanent barrier for bacteria invasion. Delivery of drugs locally from an implant surface coating rather than systemically can reduce unnecessary side effects and the amount of drug required to reach the same or better therapeutic efficacy. ${ }^{35}$ This implant surface with a growth factor coating not only offers the advantage of a high localized drug concentration but is also an effective way of delivering growth factors directly to the percutaneous site. Several previous studies have tried to fabricate implant surfaces with growth factor coatings by adsorbing antibiotics or growth factors directly to the implant surface with bone cements ${ }^{36,37}$ or by loading agents in collagen sponges, porous coatings, or polymer-based matrices. ${ }^{38,39}$ However, all of these approaches have shortcomings, which include chemical instability and local inflammatory reactions due to material composition.

The titanium nanotube was chosen as the drug carrier for making the growth factor coating because it has been shown to have good biocompatibility. In addition, previous research has clearly proven that nanotube surfaces promote bone, skin, and other tissue growth more than current conventional surfaces. ${ }^{16,20-22}$ Several papers have been published that have focused on the applications of titanium nanotube drug coatings, but none of them has examined the use of this delivery system at the percutaneous site. ${ }^{18,23,24,35}$ Titanium
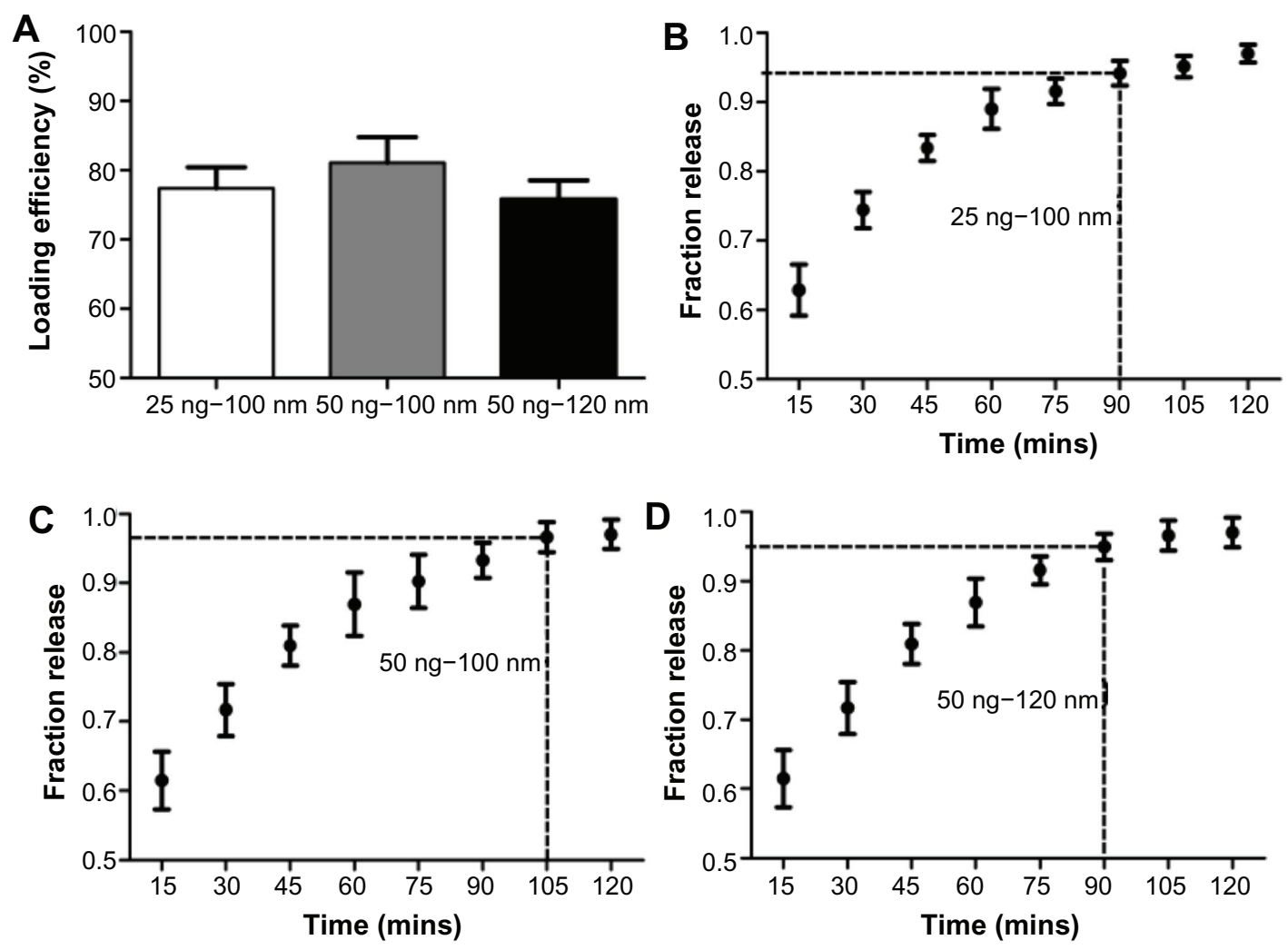

Figure 3 (A) Loading efficiency of CNN2 (connective tissue growth factor) in nanotubes; fraction of total CNN2 released from 100 nm diameter nanotubes filled with (B) $25 \mathrm{ng}$ and (C) $50 \mathrm{ng}$ of CNN2; (D) fraction of total CNN2 released from $120 \mathrm{~nm}$ diameter nanotubes filled with $50 \mathrm{ng}$ of CNN2.

Notes: The marked time point on each graph indicates when maximum protein has been released, after which the amount of additional drug eluted was negligible. Concentrations at these time points are significantly different from those at time points before $(P<0.05)$, but were not significantly different from the time points after; $n=3$. 


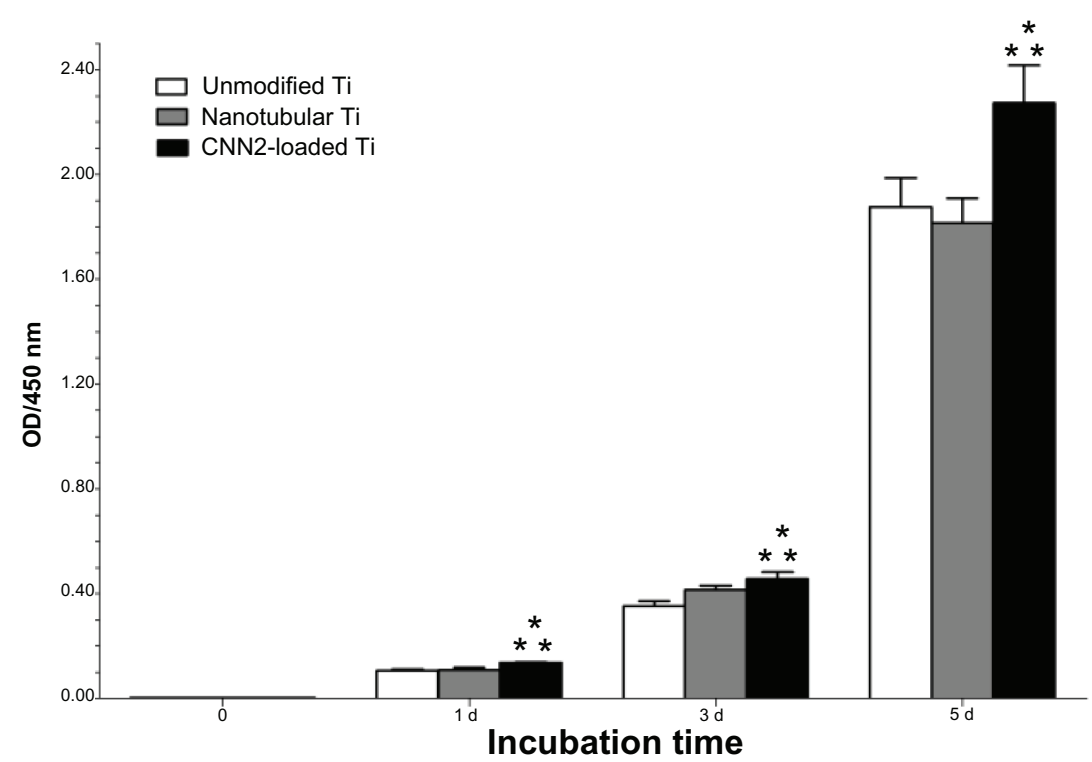

Figure 4 Cell viability on CCN2 (connective tissue growth factor)-loaded nanotubular titanium, nanotubular titanium, and unmodified titanium surfaces. Notes: $\mathrm{n}=6$; $* \mathrm{P}<0.05$ compared to nanotubular titanium; $* * \mathrm{P}<0.05$ compared to unmodified titanium.

Abbreviations: CNN2, connective tissue growth factor; $\mathrm{Ti}$, titanium.

nanotube drug-eluting coatings on the implant surface can have a variety of applications. However, the present study just focused on their use for percutaneous implants. In the present study, these nanotube surfaces showed increased hydrophilicity compared to unmodified surfaces. Therefore, these surfaces can be easily modified by organic molecules.

Recombinant human CCN2 is an $11.2 \mathrm{kDa}$ C-terminal protein that has a positive effect on fibroblasts and is a model drug. It has been shown to be sufficient to promote fibroblast adhesion via integrins, and it also promotes fibroblast proliferation. ${ }^{27-30} \mathrm{CCN} 2$ has also been shown to play a key role in mediating the formation of attachments between fibroblasts and the ECM at focal adhesions. ${ }^{40} \mathrm{CCN} 2$ gene knockout mice also display decreased expression of ECM components and matrix metalloproteinases. ${ }^{12}$ It is envisioned that other drugs with fewer detrimental side effects but of a similar size could also be loaded into nanotubular titanium to improve the interface between the implant and the soft tissue.

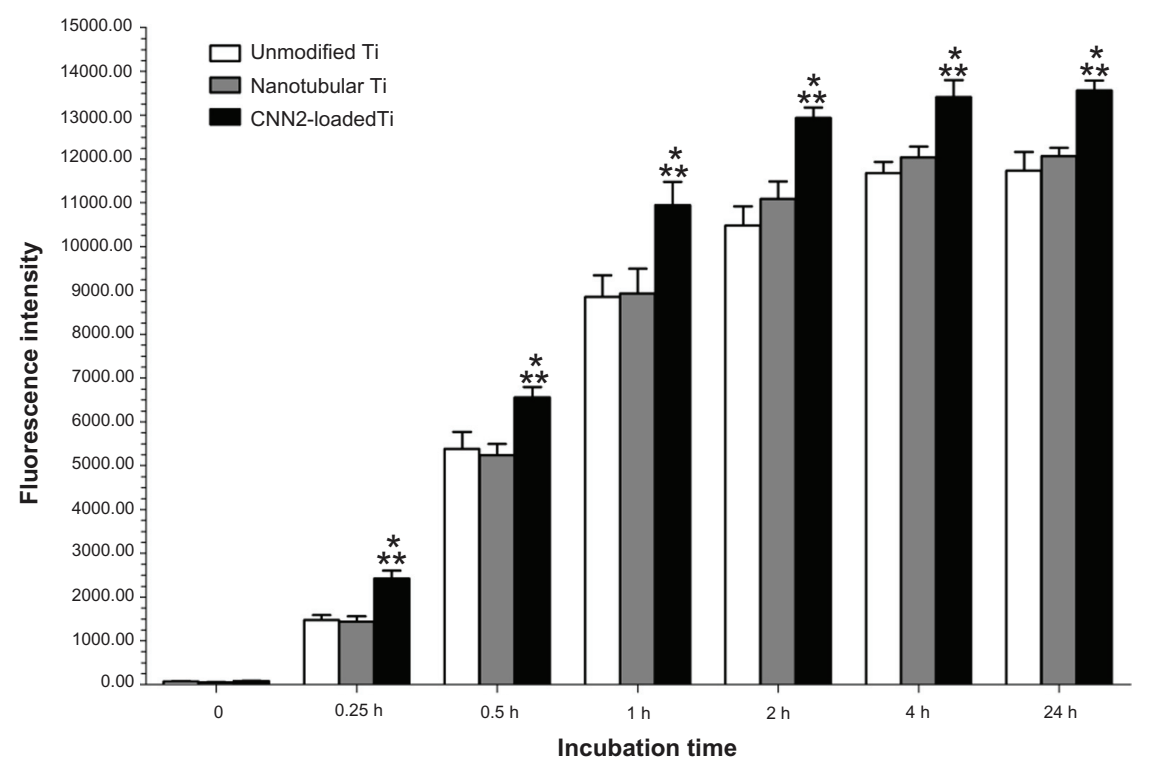

Figure 5 Increased fibroblast adhesion to CCN2 (connective tissue growth factor)-loaded nanotubular titanium. Notes: $\mathrm{n}=6$; $* \mathrm{P}<0.05$ compared to nanotubular titanium; $* * \mathrm{P}<0.05$ compared to unmodified titanium. Abbreviations: CNN2, connective tissue growth factor; Ti, titanium. 


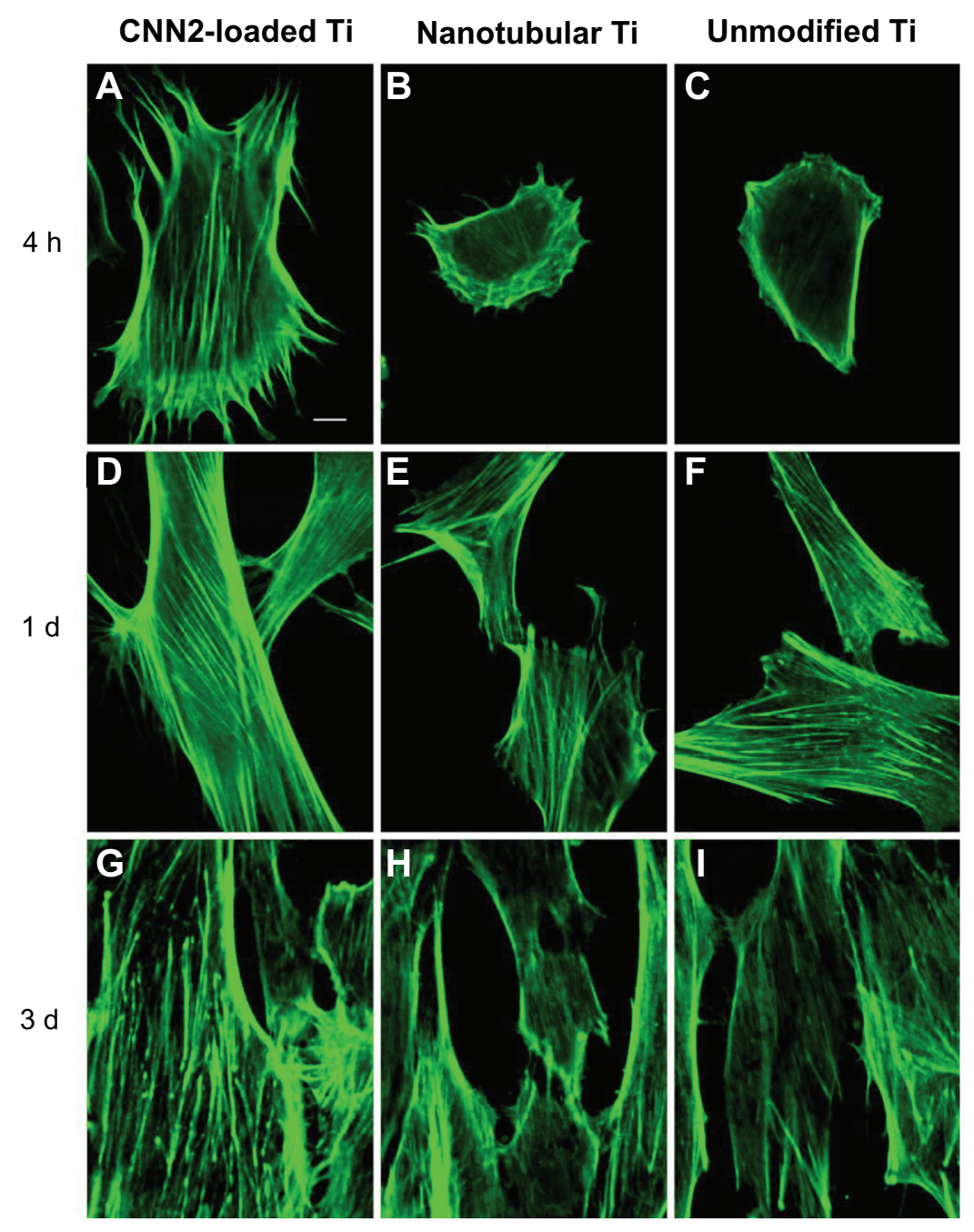

Figure 6 Fluorescent images of actin cytoskeleton among fibroblasts reacting to (A, D, and $\mathbf{G})$ CCN2 (connective tissue growth factor)-loaded nanotubular titanium, (B, E, and $\mathbf{H})$ nanotubular titanium, and $(\mathbf{C}, \mathbf{F}$, and $\mathbf{I})$ unmodified titanium surfaces after $(\mathbf{A}-\mathbf{C}) 4$ hours, (D-F) I day, and (G-I) 3 days.

Note: $\mathrm{Bar}=10 \mu \mathrm{m}$.

Abbreviations: CNN2, connective tissue growth factor; d, days; h, hours; Ti, titanium.

The results of the present study indicate that $\mathrm{CCN} 2$ released from titania nanotubes improved the functionality of fibroblasts on the titanium surface.

In the present study, the nanotubes were $100 \mathrm{~nm}$ in diameter. Although a diameter wider than $100 \mathrm{~nm}$ may significantly allow more solvent and more drug to enter the nanotubes, more drug would be lost during the rinse step as a result of the larger diameter and the lower packing density. Results showed that the loading efficiency and release time of $120 \mathrm{~nm}$ diameter nanotube were both lower than those of the $100 \mathrm{~nm}$ diameter nanotube. Another paper also demonstrated that larger diameter nanotubes $(300 \mathrm{~nm})$ can elute less drug than smaller nanotubes $(100 \mathrm{~nm})$ of the same length. ${ }^{23}$ Using a simplified lyophilization step to fill the nanotubes with $\mathrm{CCN} 2$, the loading efficiencies of the drug coating groups were both higher than $75 \%$. This means that there was little waste in the drug filling process. Other studies have also shown that the nanotube surface is hydrophilic enough for solvents to reach the maximum depth attainable by using only a capillary force-dependent filling method. Thus, any further improvements in drug loading would require the application of another filling method. ${ }^{23}$

To release protein from the nanotubes, the surfaces were immersed in PBS with orbital shaking. The release kinetics showed that the time of release for CCN2 was about 105 minutes. Some reports have shown elution times over weeks for loading with paclitaxel, sirolimus, bovine serum albumin, or silver nanoparticles that were seemingly based on different sampling without shaking. ${ }^{18,23}$ Other reports have shown similar release times. ${ }^{22,24}$ The 105 minute-released CNN2 mainly enhanced initial adhesion and cytoskeletal development of the fibroblast. Rapid and strong adhesion 
and rapid growth of the fibroblast on the implant surface would promote the formation of a permanent liquid bacterial seal in the percutaneous area and would prevent early contamination of the implant site,${ }^{15}$ which is very important for the successful formation of a permanent biologic seal. Initial adhesion and cytoskeletal development of the fibroblast means rapid growth in the subsequent period, which were proven in the results.

In the present study, although the nanotubular titanium had greater nanoscale surface roughness and higher surface energy than that of unmodified titanium, there were no statistically significant differences between the unmodified surface and the nanotubular surface in regard to fibroblast response. Recent reports have shown better cell attachment to nanotubular surfaces that are more hydrophobic than unmodified surfaces. ${ }^{20,41,42}$ But according to some results in the literature, fibroblasts prefer a smooth surface to a rough surface. ${ }^{43}$

To prevent any side effect of CNN2 in the bone healing process, a two-stage solution may be a good choice for the further clinic application of the CNN2-loaded titania nanotube surface on percutaneous implant. This would involve initially attaching a conventional component to the bone and subsequently, when the wound has already healed, inserting the percutaneous component with CNN2-loaded titanium nanotube surface.

\section{Conclusion}

This study showed the effect of a CCN2-loaded nanotubular titanium coating on fibroblast functionality. By using a simplified lyophilization method, CCN2 was loaded into nanotubes. These titania nanotubes coated with $\mathrm{CCN} 2$ underwent the elution process at a regular release rate with a release time of approximately 105 minutes. Moreover, the present study provides evidence of enhanced fibroblast adhesion and viability due to this CCN2-loaded titania nanotubular coated substrate under in vitro conditions, which also promoted actin cytoskeleton organization. The results suggest that a CCN2-loaded nanotubular titanium coating may be useful for percutaneous implants due to the beneficial effects on the formation of a soft tissue biological seal around the percutaneous site of the implant surface.

\section{Acknowledgments}

Financial support was provided by the National Natural Science Foundation of China (No. 50805141).

\section{Disclosure}

The authors report no conflicts of interest in this work.

\section{References}

1. von Recum AF. Applications and failure modes of percutaneous devices: a review. J Biomed Mater Res. 1984;18(4):323-336.

2. Gitto CA, Plata WG, Schaaf NG. Evaluation of the peri-implant epithelial tissue of percutaneous implant abutments supporting maxillofacial prostheses. Int J Oral Maxillofac Implants. 1994;9(2):197-206.

3. Jansen JA, Paquay YG, van der Waerden JP. Tissue reaction to softtissue anchored percutaneous implants in rabbits. J Biomed Mater Res. 1994;28(9):1047-1054.

4. Kim JW, Kikkawa DO, Aboy A, Glasgow BJ. Chronic exposure of hydroxyapatite orbital implants: cilia implantation and epithelial downgrowth. Ophthal Plast Reconstr Surg. 2000;16(3):216-222.

5. Knabe C, Grosse-Siestrup C, Gross U. Histologic evaluation of a natural permanent percutaneous structure and clinical percutaneous devices. Biomaterials. 1999;20(6):503-510.

6. Dasse KA. Infection of percutaneous devices: prevention, monitoring, and treatment. J Biomed Mater Res. 1984;18(4):403-411.

7. Mooney V, Schwartz SA, Roth AM, Gorniowsky MJ. Percutaneous implant devices. Ann Biomed Eng. 1977;5(1):34-46.

8. Gangjee T, Colaizzo R, von Recum AF. Species-related differences in percutaneous wound healing. Ann Biomed Eng. 1985;13(5):451-467.

9. Chehroudi B, Brunette DM. Subcutaneous microfabricated surfaces inhibit epithelial recession and promote long-term survival of percutaneous implants. Biomaterials. 2002;23(1):229-237.

10. Hamdan M, Blanco L, Khraisat A, Tresguerres IF. Influence of titanium surface charge on fibroblast adhesion. Clin Implant Dent Relat Res. 2006;8(1):32-38.

11. Yoshinari M, Matsuzaka K, Inoue T, Oda Y, Shimono M. Effects of multigrooved surfaces on fibroblast behavior. J Biomed Mater Res A. 2003;65(3):359-368.

12. Chen Y, Abraham DJ, Shi-Wen X, et al. CCN2 (connective tissue growth factor) promotes fibroblast adhesion to fibronectin. Mol Biol Cell. 2004;15(12):5635-5646.

13. Kielty CM, Shuttleworth CA. Microfibrillar elements of the dermal matrix. Microsc Res Tech. 1997;38(4):413-427.

14. Jansen JA, van der Waerden JP, de Groot K. Fibroblast and epithelial cell interactions with surface-treated implant materials. Biomaterials. 1991;12(1):25-31.

15. Jansen JA, van der Waerden JP, de Groot K. Effect of surface treatments on attachment and growth of epithelial cells. Biomaterials. 1989;10(9):604-608.

16. Puckett SD, Lee PP, Ciombor DM, Aaron RK, Webster TJ. Nanotextured titanium surfaces for enhancing skin growth on transcutaneous osseointegrated devices. Acta Biomater. 2010;6(6):2352-2362.

17. Mutsuzaki H, Ito A, Sakane M, Sogo Y, Oyane A, Ochiai N. Fibroblast growth factor-2-apatite composite layers on titanium screw to reduce pin tract infection rate. J Biomed Mater Res B Appl Biomater. 2008;86(2):365-374.

18. Zhao L, Wang H, Huo K, et al. Antibacterial nano-structured titania coating incorporated with silver nanoparticles. Biomaterials. 2011;32(24):5706-5716.

19. Cao H, Liu X, Meng F, Chu PK. Biological actions of silver nanoparticles embedded in titanium controlled by micro-galvanic effects. Biomaterials. 2011;32(3):693-705.

20. Burns K, Yao C, Webster TJ. Increased chondrocyte adhesion on nanotubular anodized titanium. J Biomed Mater Res A. 2009;88(3): 561-568.

21. Yao C, Slamovich EB, Webster TJ. Enhanced osteoblast functions on anodized titanium with nanotube-like structures. J Biomed Mater Res A. 2008;85(1):157-166.

22. Park J, Bauer S, Schlegel KA, Neukam FW, von der Mark K, Schmuki P. TiO2 nanotube surfaces: $15 \mathrm{~nm}$ - an optimal length scale of surface topography for cell adhesion and differentiation. Small. 2009;5(6):666-671.

23. Peng L, Mendelsohn AD, LaTempa TJ, Yoriya S, Grimes CA, Desai TA. Long-term small molecule and protein elution from $\mathrm{TiO} 2$ nanotubes Nano Lett. 2009;9(5):1932-1936. 
24. Popat KC, Eltgroth M, Latempa TJ, Grimes CA, Desai TA. Decreased Staphylococcus epidermis adhesion and increased osteoblast functionality on antibiotic-loaded titania nanotubes. Biomaterials. 2007;28(32):4880-4888.

25. Eaninwene G 2nd, Yao C, Webster TJ. Enhanced osteoblast adhesion to drug-coated anodized nanotubular titanium surfaces. Int $J$ Nanomedicine. 2008;3(2):257-264.

26. Roy P, Berger S, Schmuki P. TiO nanotubes: synthesis and applications. Angew Chem Int Ed Engl. 2011;50(13):2904-2939.

27. Brigstock DR, Steffen CL, Kim GY, Vegunta RK, Diehl JR, Harding PA. Purification and characterization of novel heparin-binding growth factors in uterine secretory fluids. Identification as heparin-regulated Mr 10,000 forms of connective tissue growth factor. $J$ Biol Chem. 1997;272(32):20275-20282.

28. Chen CC, Chen N, Lau LF. The angiogenic factors Cyr61 and connective tissue growth factor induce adhesive signaling in primary human skin fibroblasts. J Biol Chem. 2001;276(13):10443-10452.

29. Leask A, Abraham DJ. The role of connective tissue growth factor, a multifunctional matricellular protein, in fibroblast biology. Biochem Cell Biol. 2003;81(6):355-363.

30. Ball DK, Rachfal AW, Kemper SA, Brigstock DR. The heparinbinding $10 \mathrm{kDa}$ fragment of connective tissue growth factor (CTGF) containing module 4 alone stimulates cell adhesion. $J$ Endocrinol. 2003;176(2):R1-R7.

31. Perbal B. The CCN family of genes: a brief history. Mol Pathol. 2001;54(2):103-104.

32. Brigstock DR. The CCN family: a new stimulus package. J Endocrinol. 2003;178(2):169-175.

33. Van Beek JP, Kennedy L, Rockel JS, Bernier SM, Leask A. The induction of CCN2 by TGF $\beta 1$ involves Ets-1. Arthritis Res Ther. 2006;8(2):R36.

34. El-Ghalbzouri A, Van Den Bogaerdt AJ, Kempenaar J, Ponec M. Human adipose tissue-derived cells delay re-epithelialization in comparison with skin fibroblasts in organotypic skin culture. $\mathrm{Br} J$ Dermatol. 2004;150(3):444-454
35. Popat KC, Eltgroth M, LaTempa TJ, Grimes CA, Desai TA. Titania nanotubes: a novel platform for drug-eluting coatings for medical implants? Small. 2007;3(11):1878-1881.

36. Price JS, Tencer AF, Arm DM, Bohach GA. Controlled release of antibiotics from coated orthopedic implants. J Biomed Mater Res. 1996;30(3):281-286.

37. Silverman LD, Lukashova L, Herman OT, Lane JM, Boskey AL. Release of gentamicin from a tricalcium phosphate bone implant. J Orthop Res. 2007;25(1):23-29.

38. Friedlaender GE, Perry CR, Cole JD, et al. Osteogenic protein-1 (bone morphogenetic protein-7) in the treatment of tibial nonunions. J Bone Joint Surg. 2001;83-A Suppl 1(Pt 2):S151-S158.

39. Lind M, Overgaard S, Soballe K, Nguyen T, Ongpipattanakul B, Bünger C. Transforming growth factor- $\beta 1$ enhances bone healing to unloaded tricalcium phosphate coated implants: an experimental study in dogs. J Orthop Res. 1996;14(3):343-350.

40. Shi-Wen X, Stanton LA, Kennedy L, et al. CCN2 is necessary for adhesive responses to transforming growth factor- $\beta 1$ in embryonic fibroblasts. J Biol Chem. 2006;281(16):10715-10726.

41. Brammer KS, Oh S, Cobb CJ, Bjursten LM, van der Heyde H, Jin S. Improved bone-forming functionality on diameter-controlled $\mathrm{TiO}(2)$ nanotube surface. Acta Biomater. 2009;5(8):3215-3223.

42. Demetrescu I, Pirvu C, Mitran V. Effect of nano-topographical features of $\mathrm{Ti} / \mathrm{TiO}(2)$ electrode surface on cell response and electrochemical stability in artificial saliva. Bioelectrochemistry. 2010;79(1):122-129.

43. Brunette DM. Principles of cell behavior on titanium surfaces and their application to implanted devices. In: Brunette DM, Tengvall P, Textor M, Thomsen P, editors. Titanium in Medicine: Material Science, Surface Science, Engineering, Biological Responses, and Medical Applications. Berlin: Springer-Verlag; 2001:485-512.
International Journal of Nanomedicine

\section{Publish your work in this journal}

The International Journal of Nanomedicine is an international, peerreviewed journal focusing on the application of nanotechnology in diagnostics, therapeutics, and drug delivery systems throughout the biomedical field. This journal is indexed on PubMed Central, MedLine, CAS, SciSearch ${ }^{\circledR}$, Current Contents ${ }^{\circledR} /$ Clinical Medicine,

\section{Dovepress}

Journal Citation Reports/Science Edition, EMBase, Scopus and the Elsevier Bibliographic databases. The manuscript management system is completely online and includes a very quick and fair peer-review system, which is all easy to use. Visit http://www.dovepress.com/ testimonials.php to read real quotes from published authors. 